\title{
MANAGERIAL ELEMENTS SPECIFIC TO MILITARY LOGISTICS
}

\author{
Mihai-Bogdan ALEXANDRESCU*, Daniel-Sorin CONSTANTIN**, \\ Marius MILANDRU** \\ *Joint Logistics Command, Braşov, Romania \\ ***Nicolae Bălcescu" Land Forces Academy, Sibiu, Romania \\ alexa2bogdan@yahoo.com, cdanielsorin@gmail.com, \\ mnmilandru@yahoo.com
}

\begin{abstract}
Management, both as a science and as a reality, exists and applies to all hierarchical levels and segments of activity, including logistics. Military logistics ensures and maintains the necessary conditions for the large units and units to be able to fulfill their missions and objectives in the best possible conditions, both in peacetime and in other situations, crisis, war, etc. Its functional areas are specific to supply, maintenance, movement and transport, medical and veterinary support, and service provision. In this context, it can be said that the management of military logistics represents the science and the art of using the material resources, as well as the management of the human resources specialized in the logistic field, in order to achieve the objectives of the organization.
\end{abstract}

Keywords: military logistics, logistics management, logistics resources, logistics objectives.

\section{Introduction}

Both in theoretical and practical terms, logistics consists in materializing some analytical, research and permanent research activities aiming at optimizing the existing material resources at the level of the organization in order to master the information flows, the flow of raw materials, materials and products.

The principles of logistics are of military origin, being used for the first time in the military field, commanders being the first to give a new use to the notion of logistics.

Thus, logistics is regarded as an element of the art of war, which is considered as a practical part of the art of moving troops and material goods during military actions. The concept of logistics has been a real development and marketing delimitation especially since the 1950 s, the main factors that have contributed to the development of logistics being the following:

- the level of logistical experience in the military field and its transfer to the industrial sector;

- evolution of market demand, which served as a catalyst for redefining sales channels;

- taking into account the level of service offered to customers as a means of increasing competitiveness.

At the level of trading companies, logistics are based on supply and transportation issues, but at the level of the military organization, logistics does not focus only on a particular aspect, but on a wide range of areas.

In a general sense, military logistics is the set of principles, rules, measures and activities carried out in a unitary conception at the level of the military organization, in 
peacetime, in crisis situations and in war to provide the material resources necessary for the organization to achieve its objectives.

In terms of increasing the importance of military logistics, we associate the logisticians' assertion with modern interpretations, arguing that this will become "an essential condition of competitiveness in the current economic relations, a managerial tool"[1].

\section{Logistic management within the military organization}

Currently, many logistics specialist argue that logistics is a managerial function that optimizes activities at the organization level and supports the achievement of its objectives. It can also be said that "the fundamental objective of logistics management is to provide goods and services to customers at the lowest cost" [2].

The performance of the logistic management functions determines the functioning of the systems and mechanisms, the development of the activities and actions specific to each structure, but also the achievement of the established objectives or of the missions received.

To accomplish the objectives to be achieved, large units/units/ logistics microstructures carry out multiple work processes, and as in any military structure, they can be grouped into execution processes and management processes.

The logistic management is done by the commander/chief of the logistics structure and the subordinate management modules, which decide, order and control the way the planned logistic activities are carried out.

It assures the administrative and operational management of the sub-units and subordinate formations, in accordance with the provisions of the laws of the country, the national military doctrine, the military regulations, the orders and the provisions of the higher echelons.

The execution structure consists of elements specialized in ensuring the material conditions necessary for the conduct of the management act, which is dimensioned according to the mission and the size of the entity.

In order to achieve an efficient logistic management, it is important to establish adequate functional relationships that work both ways vertically and horizontally.

As a rule, specialized modules are designed to plan, organize and coordinate the logistical support of the actions of the units and major units whose structure they are part of.

Within the military organization, management is exerted on the logistics domain, thus forming a sphere of logistic management, this being materialized in the following figure.

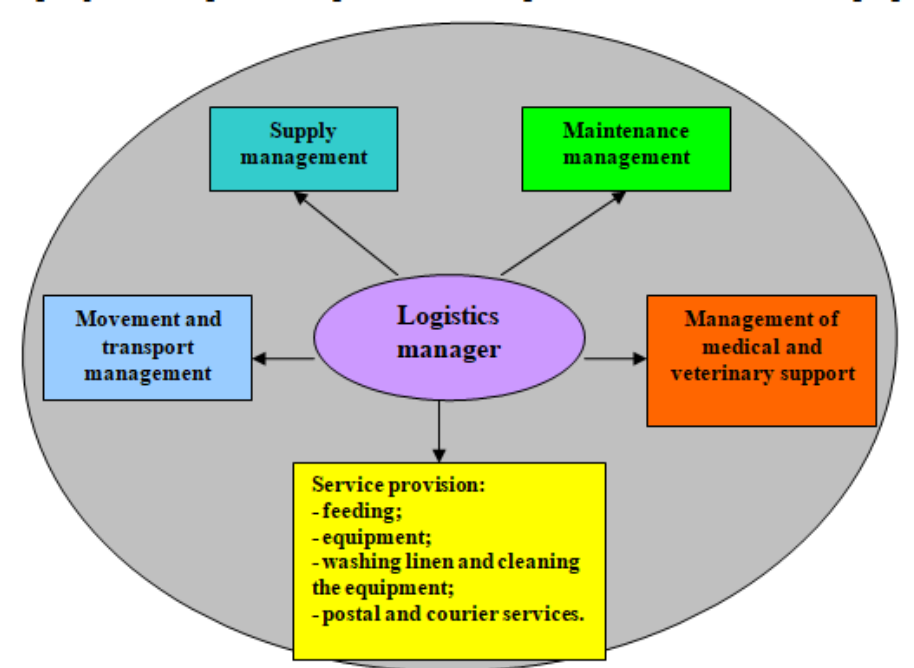

Figure no. 1: The sphere of logistics management within the military organization 
The logistic management is exercised by the commander/chief of the military structure, advised by the head of the logistic module, who must always know the logistical situation of the unit/large unit.

Managerial activities will target the following aspects:

- foundation of the necessary technology, materials and services for organizing and carrying out the activities stipulated in the planning documents;

- planning, organizing and coordinating the supply of forces with technology, equipment and materials of all categories;

- monitoring the degree of completeness of the inventory of technology and equipment and materials, as well as their storage, maintenance and exchange;

- monitoring the state of operability of the technique, armaments and materials;

- financing the necessary funds for the technical-material insurance and ensuring the use of funds allocated according to the destination;

- planning, organizing and coordinating maintenance for all categories of equipment and supplies;

- monitoring the downgrading, discarding and capitalization of the equipment and materials;

- monitoring damage to subordinate structures;

- planning and coordinating military transport;

- planning, organizing and coordinating the feeding and equipping of the staff;

- planning, organizing and executing specialized control and guidance at subordinate structures;

- monitoring the in-service behavior of fighting equipment, weapons, ammunition and new material brought into operation;

- coordination of storage activities;
- planning, organizing and coordinating the specialized training of the logistics personnel under subordination.

\subsection{Supply management}

One of the major areas of logistics within military organizations is supply, including all the activities that are being carried out to determine the need, launch demand, purchase, receive, manage and distribute the material goods.

Supply activity within the military structures of any level (force category, weapon headquarters, logistics base, operating battalion etc.) or field of activity (maintenance center, weapons and ammunition depot, technical materials warehouse, warehouse fuel, etc.) includes all the attributions by which the procurement of equipment, materials, spare parts, fuel, or other material items necessary for the fulfillment of the established missions or objectives is ensured.

Within this, an important percentage is taken by the planning of the supply/resupply activities, the identification of the material goods, the establishment of the necessary quantities in accordance with the supply and consumption rules, the conclusion of contracts, the launching of orders to the suppliers, the determination of the execution deadlines and the specific responsibilities.

Supply management is to provide current consumptions at the level of requirements, to build up and complete inventories, and to provide spare parts and materials to maintain maintenance to keep military equipment and technology in a state of operability, this is the process of planning, implementing and controlling operations with the aim of meeting the requirements of the beneficiary with maximum efficiency.

In order to carry out the specific supply activities, the necessary financial resources must be determined for their allocation through the revenue and expenditure budgets and the management and control of 
their use by the management of the units and the large units, respecting the principle of economy and priority provision of the current needs of the entity.

In this respect, the logistics management activities will mainly consist of the following:

- the establishment of needs based on the projects, the annual public procurement programs, which are developed for goods in their own purchasing power, according to the needs of consumption, use and forecasted financing;

- the insurance of the funds, the financing of the acquisition of material goods is performed by the credit release authority, according to the competences established by the legal norms.

Within the military structures, during peacetime, there are specialized entities in the field of public procurement (service, department, office, division) that have as main attributes marketing activities, market research, knowledge of consumer needs, volume and layout of products and services, setting up and running the procurement procedure and planning the necessary funds.

The staff with attributions on this segment of activity use as the main instrument of planning, monitoring and capitalizing the Annual Procurement Program, it is drawn up annually, as necessary, according to the allocated budget, by types of procedures, budgetary articles, with start/completion deadlines, but also with those responsible for each individual purchase.

\subsection{Maintenance management}

Maintenance, as a functional domain of logistics, ensures the maintenance and restoration of equipment and technology to the specific technical characteristics of operation, in order to fulfill the missions by the military structures.

Maintenance management is the process by which you know precisely how to lead and influence your staff so that they keep your technical systems in good working order.

According to the general theory of systems, any system is made up of subsystems and they can be considered systems in relation to their component elements, so we can argue that maintenance is a subsystem of the logistics system, but maintenance is a system in relation to its components.

The maintenance system integrated into the logistics of the military organization consists of all the principles, rules, human, material, and financial resources, interdependent between them cohering, meant to carry out all the actions taken to maintain and restore the technical equipment to the specific technical characteristics of operation.

For this purpose, the maintenance concept is redefined, depending on the state of the art and the time of the works, by two components, namely preventive maintenance and corrective maintenance.

The theoretical and practical approach to maintenance, in strict connection with the change of mentality in the organizational structures of the military system, leads to the necessity of realizing in peacetime an integrated, modular, flexible, adaptable maintenance system for any situation.

Conceptually, maintenance management is a set of activities, disciplines, methods, theoretical and technical models that encompass tasks of the organization's leadership as an instrument by which optimal managerial decisions can be made to train the whole team to work more efficiently.

The main management tools are specific programs and plans, exemplified by the following:

- The annual production program, based on the tasks received, hierarchically from the upper echelons, according to the competencies, the production capacity and the allocated budget;

- The annual maintenance plan, in it are planned the resources used, the technical maintenance and repairs on types of technology and equipment, the specification elements, as well as the programming of their execution in time.

Duty for maintenance is the responsibility 
of the head of the logistics module that manages and is responsible for its timely and quality execution, taking safety and staff protection measures.

The maintenance planning and management subsystem is the decision-maker in managing the specific activity, which is represented by the Head of Logistics along with the Technical Deputy-Commandant.

The Technical Deputy-Commandant is responsible for maintaining the equipment by keeping good technical and maintenance status, proper operation of all categories of equipment in the units and large units, as well as evacuation in time and repair of this technology.

The main maintenance - specific management activities consist of:

- performing control and testing (diagnosis) work;

- performing maintenance, which is of a preventive nature and is carried out in order to reduce the probability of failure by providing permanent supervision and periodic review;

- performing repairs, which may have a preventive or corrective nature, depending on when they are performed for their execution and are intended to restore the parameters that characterize the technical state to the nominal values;

- secure the evacuation of motor vehicles for repair.

\subsection{Movement and transport management}

Movement and transport management is ensured for the purpose of moving all categories of technology and materials from sources of supply to the beneficiary (subunit, unit, large unit) using their own means of transport.

The transports are usually carried out by means of the vehicle and the large units, depending on the state of the communication routes, the emergency and the quantity of materials can be employed in the transport activity the means of air transport, the main pipelines for the transport of fuels and lubricants, or railway of rolling stock.

Managerial activities will mainly focus on the following:

- conducting goods transports;

- carrying out transport of common materials;

- transports of materials from all classes for stock filling;

- execution of transport of materials from the territorial units of the fighting units for sending them to theaters of operations;

- transport of troops;

- preparation of staff and equipment for the safe execution of orderly transport missions.

Commanders of large units and units, through the specialized modules, ensure the movement and transport management, so that in the logistics bases, transport battalions are provided, and at the large unit or unit there is a microstructure of an office or a specialized division.

The organization, planning and execution of the transport is the responsibility of the chief of the logistic module, but at the same time it can be said that it is one of the important missions of the logistic planning and management bodies through the microstructure of the coordination of the movement and transport.

Planning, organization, execution, control and monitoring of the performance of the movement of national forces and transport to support them in theaters of operations is one of the priorities of the structures of movement and transport at all hierarchical levels and is carried out according to the regulations in force, for this purpose.

In order to accomplish the transport missions, the department/office/division responsible with the movement coordination has an important role, being the specialized structure of the logistic module, meant for the planning, coordination, control and monitoring of troop transports, military equipment and 
materials, according to the missions that the military organization must fulfill in peacetime.

It is the specialized body that plans, coordinates, controls and monitors the transport of troops, military equipment and materials on terrestrial (road and rail) and airway traffic routes, with military and civilian means of transport.

\subsection{Management of medical and} veterinary support

\section{Medical support management}

Managerial actions in the health sector lead to the following aspects:

- the provision of medical services by healthcare professionals for the prevention of illnesses, the diagnosis and treatment necessary for the restoration of the state of health, the medical recovery of the work and effort;

- prescribing and conducting appropriate treatment for the disease as well as complementary treatment procedures both during the period of staying in the hospital and during the ambulatory and recovery period;

- administration of medicines, sanitary materials and medical devices, according to the law.

In order to provide medical support to the Ministry of National Defense employees, there are adequate structures at the territorial level (military hospitals, pharmacies, infirmaries) as well as consulting rooms or similar medical units, with or without stationary, in the organization of large units or units, but also other authorized sanitary institutions.

Military hospitals are organized on the basis of territoriality principle, they have military structures (subunits/units/large units), providing medical assistance and medicines to the following categories of personnel: military personnel in activity; soldiers and professional soldiers (OR1OR4), including during training; pupils and students of military education institutions; reserve troops concentrated, regardless of grade, only during the concentration; family members of military personnel in activity; reserve and retired military staff, military retired; family members of military staff in reserve and retiring; veterans, widows and invalids of war, as well as other categories of persons, provided for in special laws incidental to the matter.

The management of these sanitary units is ensured by the board of directors, the managing committee and by the hospital director/manager, which has the tasks and objectives established by the management contract.

Within the units and large units a specialized structure is provided in the organizational chart (consulting rooms, unit infirmary), designed to plan, organize and coordinate the sanitary support of the actions/activities.

The specific activities are managed by the chief physician; he coordinates his/her own microstructure, having the following responsibilities and competencies:

- planning, organizing and coordinating healthcare;

- planning, organizing and coordinating the execution of the periodical medical check-up of military personnel and civilian staff;

- managing inventory of materials and equipment, storage, maintenance and replacement;

- keeping track of the statistics of the technology and equipment;

- substantiating the need for funds for medical insurance and ensuring the use of funds allocated according to the destination;

- planning, organizing and executing control and expert guidance in subordinate structures;

- coordinating specialized training of subordinate military personnel and making training proposals through courses.

Sanitary-veterinary support management 
Health and veterinary support is the activity that specialists carry out for the protection of animal health, the prevention and control of epizootic outbreaks, the control and the veterinary sanitary veterinary expertise of animal food products.

Therefore, the veterinary sanitary support is the object of those large units or units which have animals included in the organizational chart (rangers, ammunition or materials depots etc.).

At the same time, each military structure organizing the feeding of its own manpower must have a veterinary sanitary authorization, which is granted by specialized and competent bodies.

The management of the sanitary veterinary support is provided by the staff with attributions in this field of activity and mainly targets the following aspects:

- performing a permanent and systematic control of the animal health status;

- continuously supervising and guiding activities related to compliance with animal hygene conditions in the establishment and rigorous application of anti-epizootic measures;

- controlling how feeding of animals is done, the quality of the fodder, water, and how to use them for service or production;

- carrying out a permanent check on the healthfulness of products of animal origin in order to prevent food poisoning and communicable diseases from animals to humans;

- continuous training of animal carers on how to maintain, feed and use animals for service and production;

- providing with biological products, medicines, instrumental and other materials for all the sanitary-veterinary units.

\subsection{Service provision management}

Within the military organization, in peacetime, service management includes the provision of food and equipment rights to military staff, washing and cleaning of equipment, cleaning, deratization and pest control, postal and courier services, as well as ensuring accommodation.

The management of these services is ensured by specialized logistics microstructures under the direct coordination and guidance of the logistics manager (head of logistics, head of procurement department, platoon commander etc.).

Specific service activities will be organized, planned, deployed and controlled according to the responsibilities, competencies and expertise of each subdomain.

The organization of staff feeding is the attribute of the head of the logistics department of the large unit/unit, ensuring that the following activities are carried out:

- serving as a cooked meal of a hot meal a day (snack) - on working days by all staff;

- organizing the feeding points/buffets, both at its premises and at the place where the military personnel perform their activity, disposing pre-cooked or custom-made dishes and uncooked/ready-to-eat products;

- validation, with the approval of the commander/chief of the military unit, of surplus agri-food products with shortterm preservation, resulting from fluctuations in flocks.

Within military structures (commands, large units, units) feeding is provided for the military personnel in activity, sergeantsprofessional soldiers, students and pupils of the military educational institutions, reserve military personnel and civilian employees. Within the large units and units, the equipment is under the responsibility of the head of the logistics and the specialized departments under his/her subordination, currently the equipment of the staff is carried out in accordance with the provisions of the specialized instructions regulating this activity.

The specialized bodies and the staff with attributions in this field of activity will 
determine the necessary items for the equipment, also the quantity stipulated by the norms, the staffs according to the organizing states.

Professional soldiers are given priority to the military uniform for training, according to the rules in force, and after fully securing it; they receive the military service uniform, in stages, according to the budget funds allocated for this purpose.

Washing of linen and cleaning of the equipment is carried out by means of the cleaners of the economic operators, thus concluding service contracts or by the laundries from the structure of the large units/units.

Deratization and pest control is carried out through the economic operators in the barracks where the large units / units are disposed, usually once a year, or whenever necessary, the responsibility for organizing these activities lies with the logistics structure through the medical bodies

\section{Conclusions}

Logistics management is the process by which the functions of planning, organizing and managing a set of actions/activities and efficient use of the human, material and financial resources available to achieve the objectives, orders and tasks received are achieved.

The exercise of logistics management functions is reflected in a distinct field of military organization management, and has interdependence with other systems and fields of activity within any structure, regardless of size, complexity or rank.

The above-mentioned aspects lead us to believe that within the military organization the logistics-specific management must lead to the achievement of the specific attributions of the logistics structures determining the achievement of the objectives by the large units and the organic units they belong to.

The importance of logistics management within the military organization stems both from the need to ensure and efficiently use logistics resources, but also from the optimal functioning of the logistics elements within the structure of units and large units.

We believe that efficient logistics management can ensure the efficient use of the material resources available to the military organization as well as the fulfillment under performance conditions of its specific and general objectives.

\section{References}

[1] Minculete, Gh., Modern Approaches to Logistics Management, Publishing House of the National Defense University "Carol I", Bucharest, 2015, page 18

[2] Minculete, Gh., Udrescu, M., Andronic, B., Elements of Economic Logistics, Publishing House of the National Defense University "Carol I", Bucharest, 2010, p. 13.

[3] School of MAGTF Logistics (SOML) - www.mcu.usmc.mil/SOML. 